\title{
Comparison of Cardiovascular Mortality in the Great East Japan and the Great Hanshin-Awaji Earthquakes - A Large-Scale Data Analysis of Death Certificates -
}

\author{
Misa Takegami, PhD; Yoshihiro Miyamoto, MD; Satoshi Yasuda, MD; Michikazu Nakai, PhD; \\ Kunihiro Nishimura, MD; Hisao Ogawa, MD; Ken-ichi Hirata, MD; Ryuji Toh, MD; \\ Yoshihiro Morino, MD; Motoyuki Nakamura, MD; Yasuchika Takeishi, MD; \\ Hiroaki Shimokawa, MD; Hiroaki Naito, MD
}

\begin{abstract}
Background: Large earthquakes have been associated with cardiovascular disease (CVD) mortality. In Japan, the 1995 Great Hanshin-Awaji (H-A) Earthquake was an urban-underground-type earthquake, whereas the 2011 Great East Japan (GEJ) Earthquake was an ocean-trench type. In the present study, we examined how these different earthquake types affected CVD mortality.
\end{abstract}

\begin{abstract}
Methods and Results: We examined death certificate data from 2008 to 2012 for 131 municipalities in Iwate, Miyagi, and Fukushima prefectures ( $n=320,348)$ and from 1992 to 1996 for 220 municipalities in Hyogo, Osaka, and Kyoto prefectures $(n=592,670)$. A Poisson regression model showed significant increases in the monthly numbers of acute myocardial infarction (AMI)-related deaths (incident rate ratio [IRR] GEJ=1.34, $P=0.001$; IRR of $H-A=1.57$, $\mathrm{P}<0.001$ ) and stroke-related deaths (IRR of $\mathrm{GEJ}=1.42, \mathrm{P}<0.001$; IRR of $\mathrm{H}-\mathrm{A}=1.33, \mathrm{P}<0.001$ ) after the earthquakes. Two months after the earthquakes, AMI deaths remained significant only for $\mathrm{H}-\mathrm{A}(\mathrm{IRR}=1.13, \mathrm{P}=0.029)$. When analyzing the standardized mortality ratio (SMR) after the earthquakes using the Cochran-Armitage trend test, seismic intensity was significantly associated with $\mathrm{AMI}$ mortality for 2 weeks after both the GEJ ( $P$ for trend=0.089) and $\mathrm{H}-\mathrm{A}$ earthquakes ( $P$ for trend=0.005).
\end{abstract}

Conclusions: Following the GEJ and H-A earthquakes, there was a sharp increase in CVD mortality. The effect of the disaster was sustained for months after the H-A earthquake, but was diminished after the GEJ Earthquake. (Circ J 2015; 79: 1000-1008)

Key Words: Acute myocardial infarction; Great East Japan Earthquake; Hanshin-Awaji Earthquake; Stroke

$\mathbf{T}$ he Great East Japan (GEJ) Earthquake struck the northeast region of Japan in 2011 and was the most powerful earthquake ever recorded in Japan. It had a magnitude of 9.0 on the Richter scale and the ensuing tsunamis reached $38 \mathrm{~m}$ above sea level. The damage was devastating: 19,074 people died, and 127,361 homes were destroyed. ${ }^{1}$

There are several reports worldwide that an increase in cardiovascular disease (CVD), including sudden cardiac death and acute myocardial infarction (AMI), occurs after large earthquakes..$^{2-5}$ In the case of the GEJ Earthquake, there were increased incidents of CVD, pneumonia, acute heart failure and sudden death..$^{6-9}$ In addition, after the Great HanshinAwaji (H-A) Earthquake, an increase in the occurrence of stroke was also reported. ${ }^{10}$ However, the incidence of CVD

Received February 24, 2015; revised manuscript received March 31, 2015; accepted April 1, 2015; released online April 24, 2015 Time for primary review: 13 days

Department of Preventive Medicine and Epidemiologic Informatics (M.T., Y. Miyamoto, M. Nakai, K.N.), Department of Cardiovascular Medicine (S.Y.), National Cerebral and Cardiovascular Center, Suita; National Cerebral and Cardiovascular Center, Suita (H.O., H.N.); Division of Cardiovascular Medicine, Department of Internal Medicine (K.H.), Division of Evidence-based Laboratory Medicine (R.T.), Kobe University Graduate School of Medicine, Kobe; Division of Cardiology, Department of Internal Medicine, Iwate Medical University School of Medicine, Morioka (Y. Morino, M. Nakamura); Department of Cardiology and Hematology, Fukushima Medical University, Fukushima (Y.T.); and Department of Cardiovascular Medicine, Tohoku University Graduate School of Medicine, Sendai (H.S.), Japan

The Guest Editor for this article was Kazuo Kimura, MD.

This paper was presented at the $79^{\text {th }}$ Annual Scientific Meeting of the Japanese Circulation Society, Late Breaking Cohort Studies 1-4 (April 24, 2015, Osaka, Japan).

Mailing address: Misa Takegami, PhD, Department of Preventive Medicine and Epidemiologic Informatics, National Cerebral and Cardiovascular Center, 5-7-1 Fujishiro-dai, Suita 565-8656, Japan. E-mail: takegami-kyt@ umin.ac.jp

ISSN-1346-9843 doi:10.1253/circj.CJ-15-0223

All rights are reserved to the Japanese Circulation Society. For permissions, please e-mail: cj@j-circ.or.jp 
Table 1. Comparison Between the Great East Japan Earthquake and Great Hanshin-Awaji Earthquake ${ }^{1,11-13}$

Date

Magnitude

Earthquake type

Area characteristic

Main damage

Completely-destroyed houses

Causalities

Cause of death
The Great East Japan Earthquake

March 11, 2011, at 14:46 hours

9.0

Off-shore, ocean-trench type

Rural

Tsunami

127,361

19,074 dead

2,633 missing persons (at September 1, 2014)

Drowning (>90\%)
The Great Hanshin-Awaji Earthquake

January 17,1995 , at 5:46 hours

7.3

Underground type

Urban

Building collapse, and fire disaster

104,906

6,434 dead

3 missing persons (at May 19, 2006)

Suffocation or crushing (>70\%)

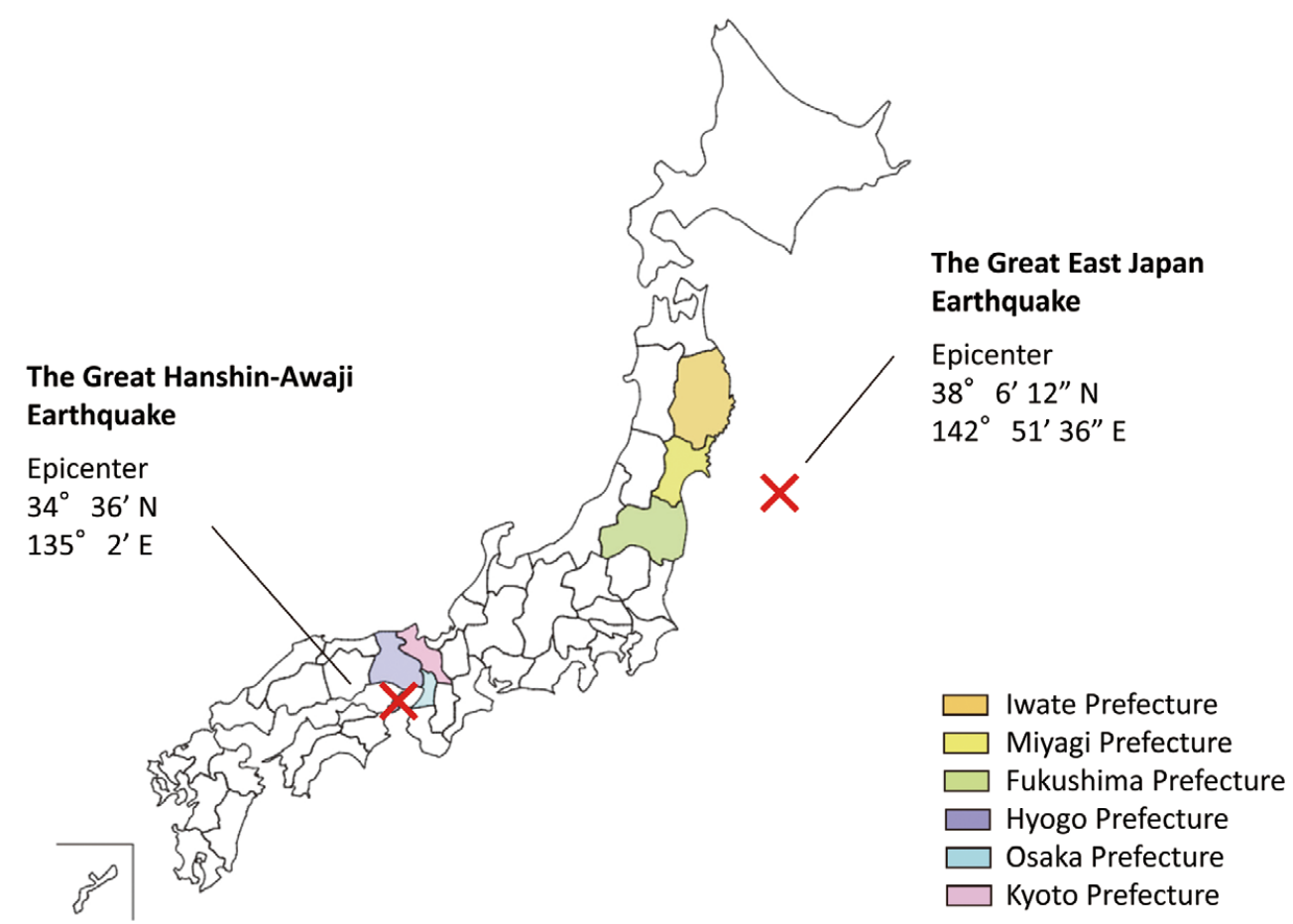

Figure 1. Locations of the epicenters of the Great East Japan Earthquake and the Great Hanshin-Awaji Earthquake, and the study areas.

mortality related to the GEJ Earthquake has not been investigated.

The H-A Earthquake with a magnitude of 7.2 was the second largest natural disaster to occur in Japan in the past 50 years. It hit the southern part of Hyogo Prefecture on January 17, $1995 .{ }^{11}$ After the H-A Earthquake (6,434 total deaths) there was an increase in stroke and AMI. ${ }^{5,10}$ Awaji Island and Kobe city were the only areas that were studied; however, the effect of seismic intensity on AMI mortality remains unknown.

An increase in mortality related to CVD after large earthquakes has been reported, but the research studies did not focus on earthquake type. The H-A Earthquake was an urbanunderground type, and the GEJ Earthquake was an off-shore, ocean-trench type (Table 1).11-13 There is no evidence that differences in the damage caused by the earthquakes increased the CVD mortality rate.
The present study was designed to determine whether (1) the type of earthquake and (2) seismic intensity has an effect on CVD. With this aim, we analyzed the extent of increased deaths from AMI and stroke in 3 prefectures that included most of the areas affected by the H-A and GEJ Earthquakes.

\section{Methods}

Population and Study Area

The GEJ Earthquake occurred on March 11, 2011. The epicenter was located at 38 degrees latitude, 19 min north, and 142 degrees longitude, 22 min east. ${ }^{1}$ The disaster area widely encompassed East Japan. Our study included data from 131 municipalities that sustained severe damage from the earthquake: 13 cities and 20 municipalities in Iwate prefecture; and 4 districts of Sendai city, 12 other cities and 22 municipalities 


\begin{tabular}{|c|c|c|c|c|c|c|c|c|c|}
\hline \multirow{2}{*}{ Year } & \multicolumn{4}{|c|}{ The Great East Japan Earthquake (2011) } & \multirow{2}{*}{ Year } & \multicolumn{4}{|c|}{ The Great Hanshin-Awaji Earthquake (1995) } \\
\hline & Iwate & Miyagi & Fukushima & Total & & Hyogo & Osaka & Kyoto & Total \\
\hline 2008 & 15,042 & 20,722 & 21,617 & 57,381 & 1992 & 39,098 & 56,226 & 19,119 & 114,443 \\
\hline 2009 & 15,434 & 20,873 & 21,602 & 57,909 & 1993 & 40,222 & 57,728 & 19,525 & 117,475 \\
\hline 2010 & 15,784 & 21,984 & 22,804 & 60,572 & 1994 & 40,012 & 57,024 & 19,133 & 116,169 \\
\hline 2011 & 22,362 & 34,052 & 26,150 & 82,564 & 1995 & 47,771 & 59,604 & 19,628 & 127,003 \\
\hline 2012 & 16,168 & 22,287 & 23,467 & 61,922 & 1996 & 39,691 & 58,497 & 19,392 & 117,580 \\
\hline
\end{tabular}

in Miyagi prefecture; and 13 cities and 46 municipalities in Fukushima prefecture (Figure 1). The total number of human casualties from the study area included $99.4 \%$ of the total number of human casualties from the GEJ Earthquake. ${ }^{1}$

The H-A Earthquake occurred on January 17, 1995. The epicenter was located at 34 degrees latitude, 36 min north, and 135 degrees longitude, 2 min east. ${ }^{11}$ The main disaster area was the Hyogo prefecture. The study area for the H-A Earthquake included 220 municipalities: 9 districts consisted of Kobe city, 20 other cities and 70 municipalities in the Hyogo prefecture; 24 districts comprising Osaka city, 32 other cities and 11 municipalities in the Osaka prefecture; and 11 districts comprising Kyoto city, 10 other cities and 33 municipalities in the Kyoto prefecture (Figure 1). The number of human causalities in Hyogo prefecture included $99.5 \%$ of the total number of human causalities in the $\mathrm{H}$-A Earthquake $(6,402 / 6,434) .^{12}$

\section{Data Collection}

We examined death certificate data between 2008 and 2012 from the 131 municipalities in Iwate, Miyagi, and Fukushima prefectures ( $n=320,347$; GEJ), and between 1992 and 1996 in 220 municipalities in Hyogo, Osaka, and Kyoto prefectures $(\mathrm{n}=592,670 ; \mathrm{H}-\mathrm{A})$. The death certificate data were provided by the Ministry of Health and Welfare in Japan with official permission, and included date of death, date of birth, sex, underlying cause of death and the area code for each decedent. The cause of death was coded according to the International Classification of Diseases, 9th Revision (ICD-9) (1994) and 10th Revision (ICD-10) (1995).

In order to calculate the death rates for the 5 years before and after the earthquakes, we obtained population data from the annual reports of the study area, which are based on the population Residential Register of Japan. ${ }^{14}$ We extrapolated the population data from 1992 to 1994 using 1995 data because there was a lack of data prior to 1995 .

Information on seismic intensity was obtained from the Japan Meteorological Agency. ${ }^{15}$ We used the maximum seismic intensity, as categorized by Japan Meteorological Agency's Intensity scale (JMAI scale). Seismic intensity was measured in a total of 291 stations, and we processed the data using the location information of city halls from municipalities in Iwate, Miyagi and Fukushima Prefectures. However, the seismic intensity was measured in only 179 stations in 1995, which covered 64 municipalities in Hyogo (26 municipalities), Osaka (24 municipalities) and Kyoto prefectures (12 municipalities). ${ }^{15}$

This study was approved by the Institutional Review Board of the National Cerebral and Cardiovascular Center.

\section{Statistical Analysis}

We counted the deaths from AMI (ICD-9 410; ICD-10 I2122) and stroke (ICD-9 430-438; ICD-10 I60-69) at monthly intervals and designated the day of the earthquake as the starting point. Monthly death rates of AMI and stroke after the earthquakes were compared with mean values in the same month from 3 previous years as a reference using a Poisson regression model. The Poisson regression model was similarly applied to data from the year immediately after the H-A Earthquake as a reference, because the ICD was considerably modified in 1995. In addition, because damage from the H-A Earthquake was concentrated in Hyogo prefecture ( $>90 \%$ of the deaths occurred in Hyogo prefecture), a similar analysis limited to Hyogo prefecture was performed.

The standardized mortality ratio (SMR) in each municipality for 2 weeks, 1 month, 9 months and 1 year following each earthquake was calculated using the AMI and stroke death rates from 3 previous years as a reference for the GEJ Earthquake. Similarly, the SMR was calculated during intervals in 1996 and used as a reference for the H-A Earthquake. The effect of seismic intensity, and excessive AMI and stroke mortality (SMR $\geq 2$ ) were analyzed using the Cochran-Armitage trend test for 2 weeks, and 1 month after the earthquakes.

SAS statistical software was used for all analyses and a P-value of less than 0.05 was considered as statistically significant.

\section{Results}

The total number of deaths in Iwate, Miyagi, and Fukushima prefectures between 2008 and 2012 was 320,348. In Hyogo, Osaka, and Kyoto prefectures between 1992 and 1996, the total was 592,670. On comparing data, from 2008 to 2010 with the data from the year of each earthquake, the number of deaths increased in all prefectures. The largest increase was in Miyagi prefecture following the GEJ Earthquake and in Hyogo prefecture following the H-A Earthquake (Table 2). The percentages of the population aged $\geq 65$ years in the 3 prefectures affected by the GEJ Earthquake were $20.6 \%$ for men and $27.4 \%$ for women. In contrast, the percentages in the 3 prefectures of the H-A Earthquake were $10.7 \%$ for men and $15.1 \%$ for women (Table S1).

Figure 2 shows the death rates (per 100,000) from AMI and stroke in the study area affected by the GEJ Earthquake from January 11, 2008 to December 10, 2012. One year after the earthquake, the total number of AMI deaths amounted to 2,799 (48.5 per 100,000) and stroke deaths were 8,004 (138.5 per 100,000). These data showed that the AMI and stroke death rates were higher than in other years.

The mortality per month from CVD tended to be higher in the winter and lower in the summer in all years. We compared the monthly occurrence of AMI deaths and stroke deaths immediately after the GEJ Earthquake to the same months in the 3 previous years using a Poisson regression model. The incident rate ratio (IRR) for AMI deaths was 1.39 (95\% confidence interval [95\% CI], 1.13-1.58) and the IRR for stroke 


\section{A AMI}

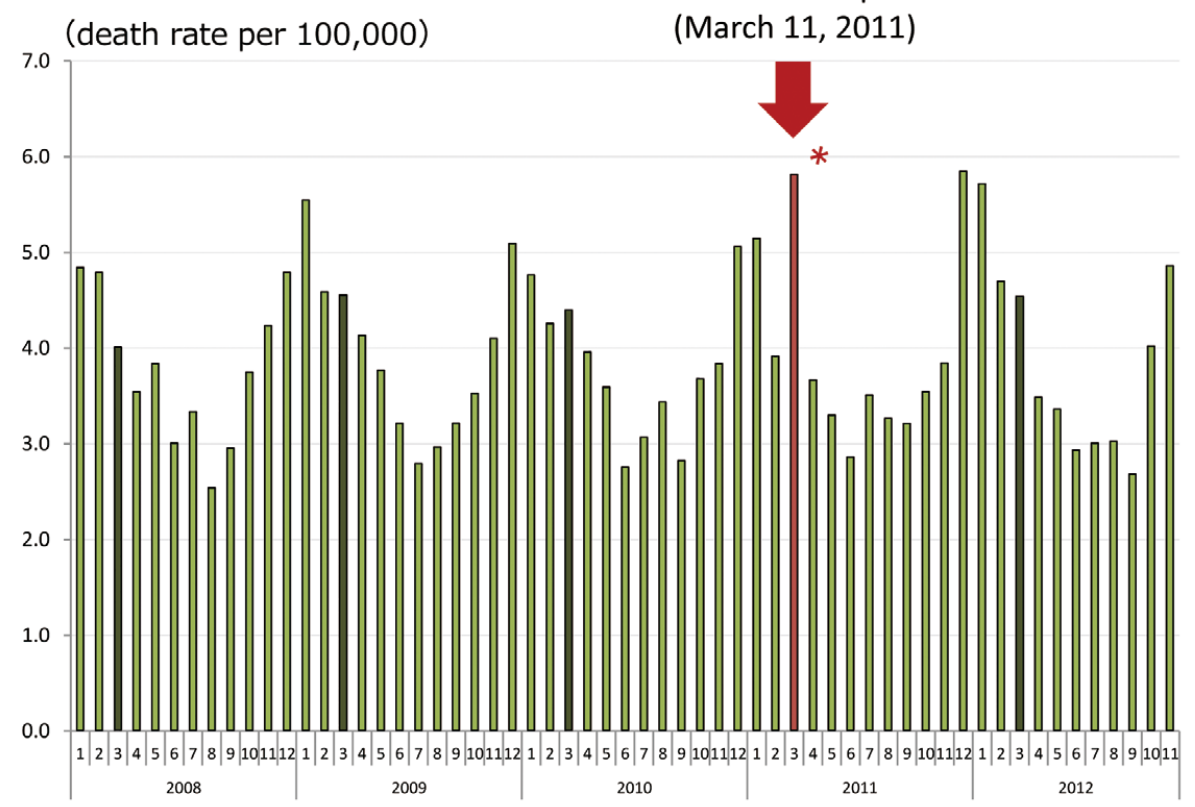

\section{B Stroke}

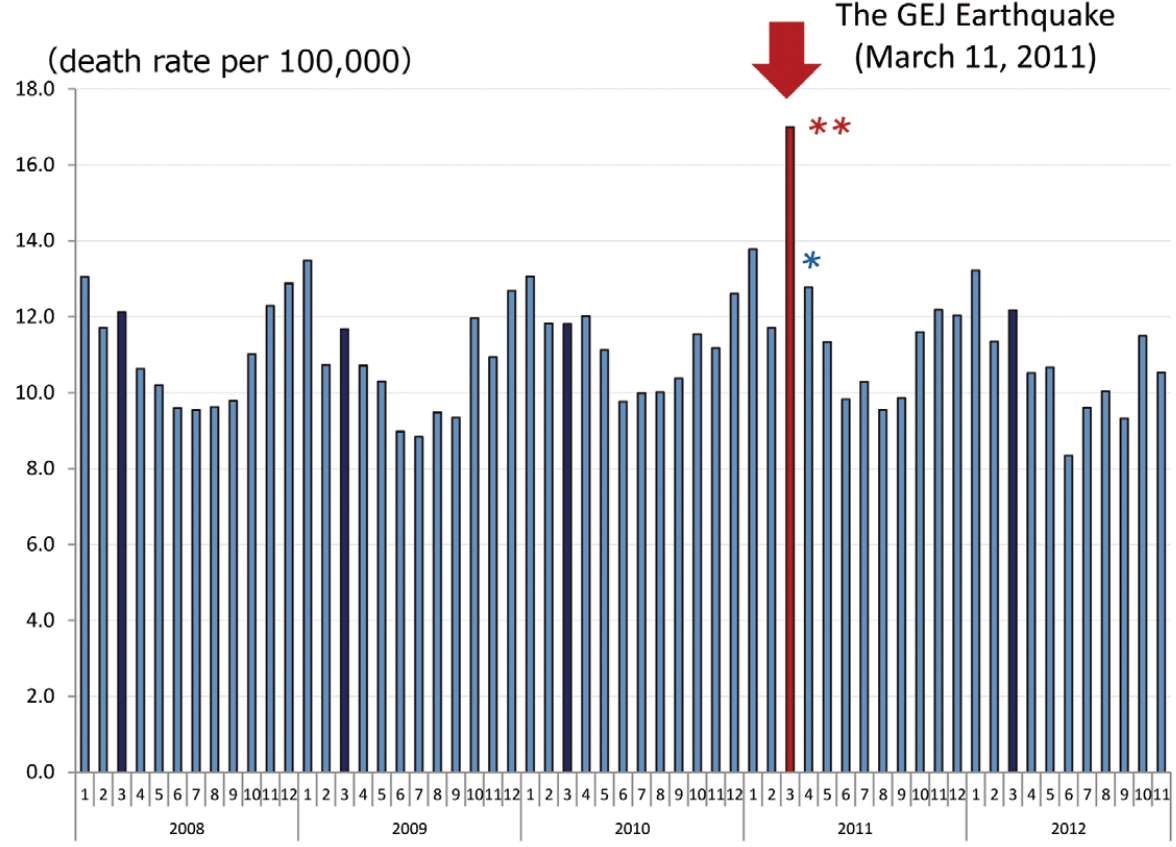

Figure 2. Monthly death rates from January 11, 2008 to December 10, 2012 for AMI (A) and stroke (B) in Iwate, Miyagi and Fukushima prefectures. Red arrows indicate the occurrence of the Great East Japan (GEJ) Earthquake. ${ }^{\star} P<0.001,{ }^{\star \star} P<0.05$ : comparison with the reference, which was the means of the number of AMI and stroke deaths in the same months for the previous 3 years. AMI, acute myocardial infarction.

deaths was 1.42 (95\% CI, 1.29-1.57) in the year after the GEJ Earthquake. A sharp increase in the AMI death rate was only observed during the first month following the GEJ Earthquake, but a significant increase continued for 2 months
(Table 3).

Figure 3 shows death rate (per 100,000) from AMI and stroke in the study area affected by the H-A Earthquake from January 17, 1992 to December 16, 1996. The total number of 


\begin{tabular}{|c|c|c|c|c|c|c|}
\hline & & AMI & & & Stroke & \\
\hline & IRR & $95 \% \mathrm{Cl}$ & $P$ value & IRR & $95 \% \mathrm{Cl}$ & $P$ value \\
\hline \multicolumn{7}{|c|}{ Great East Japan Earthquake (2011) ${ }^{\star}$} \\
\hline Mar 11-Apr 10 & 1.34 & $(1.13-1.58)$ & 0.001 & 1.42 & $(1.29-1.57)$ & $<0.001$ \\
\hline Apr 11-May 10 & 0.96 & $(0.78-1.14)$ & 0.521 & 1.14 & $(1.03-1.27)$ & 0.014 \\
\hline May $11-J u n ~ 10$ & 0.88 & $(0.72-1.07)$ & 0.194 & 1.07 & $(0.96-1.20)$ & 0.236 \\
\hline Jun 11-Jul 10 & 0.95 & $(0.77-1.18)$ & 0.640 & 1.03 & $(0.92-1.16)$ & 0.576 \\
\hline \multicolumn{7}{|c|}{ Great Hanshin-Awaji Earthquake (1995)* } \\
\hline Jan 17-Feb 16 & 1.57 & $(1.42-1.73)$ & $<0.001$ & 1.33 & $(1.25-1.43)$ & $<0.001$ \\
\hline Feb 17-Mar 16 & 1.13 & $(1.01-1.26)$ & 0.029 & 1.13 & $(1.05-1.21)$ & 0.001 \\
\hline Mar 17-Apr 16 & 1.11 & $(1.00-1.24)$ & 0.053 & 1.01 & $(0.94-1.09)$ & 0.716 \\
\hline Apr 17-May 16 & 1.03 & $(0.91-1.17)$ & 0.613 & 0.99 & $(0.91-1.07)$ & 0.720 \\
\hline
\end{tabular}

${ }^{*}$ Compared with AMl and stroke deaths in the same months in the previous 3 years in the Great East Japan Earthquake, and the year following the Great Hanshin-Awaji earthquake. AMI, acute myocardial infarction; $\mathrm{Cl}$, confidence interval; IRR, incident rate ratio.

deaths from AMI and stroke at 1 year after the earthquake amounted to 6,800 (41.1 per 100,000), and 16,425 (99.3 per 100,000), respectively. Again, the number of AMI and stroke deaths was higher than in other years.

In the H-A Earthquake, the monthly death rates for both AMI and stroke significantly increased after the earthquake (IRR for AMI=2.07 [95\% CI, 1.85-2.31], IRR for stroke=1.62 [95\% CI, 1.51-1.74]) compared with the same months in the previous 3 years. In addition, similar results were also observed during the same months in 1996, although modifications to ICD-10 must be considered (IRR for AMI=1.57 [95\% CI, 1.42-1.74], IRR for stroke=1.33 [95\% CI, 1.25-1.43]). A significant increase in both the AMI and stroke death rates was observed during the first 2 months following the H-A Earthquake (Table 3). A similar trend was seen in the analysis limited to Hyogo prefecture (IRR for $\mathrm{AMI}=1.88[95 \% \mathrm{CI}$, 1.59-2.23], IRR for stroke $=1.38$ [95\% CI, 1.24-1.54]).

Figure 4 shows the percentage of municipalities where there was a SMR $\geq 2$ for AMI and stroke for 2 weeks, 1 month, 9 months and 1 year following the GEJ and H-A Earthquakes. One month after the GEJ Earthquake, $15.3 \%$ of municipalities had a SMR $\geq 2$ for AMI deaths, and $13.0 \%$ for stroke deaths. There were $8.4 \%$ of municipalities with SMR $\geq 2$ for AMI even 1 year after the GEJ Earthquake. One month following the H-A Earthquake, the peak numbers of municipalities showed SMR $\geq 2$ for both AMI deaths $(29.7 \%)$ and stoke deaths $(25.0 \%)$. SMRs for both AMI death and stroke death decreased in most municipalities at 1 year after the H-A Earthquake.

Figure 5 shows the association between $S M R \geq 2$ for AMI and stroke mortality and seismic intensity using the CochranArmitage trend test. The municipalities in the study areas were divided into 3 categories by using the JMAI scale, which is a seismic indicator. Of the 131 municipalities in the GEJ Earthquake area, $29(22.1 \%)$ were classified as $<5.0$ on the JMAI scale; $77(58.8 \%)$ were $<6.0$ and $25(19.1 \%)$ were $>6.1$. Of the 64 municipalities in the H-A Earthquake area, $33(51.6 \%)$ were categorized as $<5.0$ on the JMAI scale; $12(18.8 \%)$ were $<6.0$ and $19(29.7 \%)$ were $>6.1$. There were marginally significant associations between AMI mortality and seismic intensity for 1 month after the GEJ Earthquake ( $P$ for trend=0.081). The seismic intensity was significantly associated with AMI mortality for only 2 weeks following the H-A Earthquake (P for trend $=0.005)$. On the other hand, there was no association between deaths from stroke and seismic intensity after either the GEJ or the H-A Earthquake.

\section{Discussion}

The present study shows that 1 month after the GEJ Earthquake and the H-A Earthquake, there was a sharp increase in AMI and stroke mortality. The effect on AMI mortality was sustained for months after the H-A Earthquake, but not after the GEJ Earthquake. To our knowledge, this is the first report that used similar data to compare the effect of different types of major earthquakes on CVD mortality among a large population. In addition, there is evidence that AMI mortality was associated with seismic intensity, whereas stroke mortality showed no association with seismic intensity.

The current results indicted increased AMI and stroke mortality rates after both earthquake disasters. Our findings are consistent with most previous studies. ${ }^{5,16,17}$ For 2 months after the H-A Earthquake and for 1 month after the GEJ Earthquake, there was an increased mortality from AMI. Stroke mortality continued for 2 months after both earthquakes. The H-A Earthquake seems to have had a more prolonged effect on AMI mortality than the GEJ Earthquake. It has been reported that AMI mortality increased for 8 weeks after the H-A Earthquake, ${ }^{5}$ in comparison with previous earthquakes, including the Northridge Earthquake. ${ }^{17}$ The Northridge Earthquake was also an underground-type and was the same type as the H-A Earthquake, though damage was less than the H-A Earthquake. The GEJ Earthquake caused more severe damage and approximately 3-fold more human causalities as the H-A Earthquake. The percentage of the population aged $\geq 65$ years was higher in the 3 prefectures that were included in the study for the GEJ Earthquake than in the 3 prefectures included in the study for the H-A Earthquake. However, in examining the incidence of AMI and stroke, the data for the previous 3 years in each region were used as reference data. Therefore, earthquake type or size and the difference in age distribution cannot account for the prolonged duration of increased cardiac mortality from the H-A Earthquake. We speculate that the prolonged duration that occurred after the H-A Earthquake ${ }^{5}$ was not seen after the GEJ Earthquake because of differences in hospital function. For example, disaster response times and quicker access to medical treatment may have evolved because of the valuable lessons learned during the H-A Earthquake. In Japan, the necessity of establishing Disaster Medical Assistance Teams (DMATs) was recognized after the H-A Earth- 


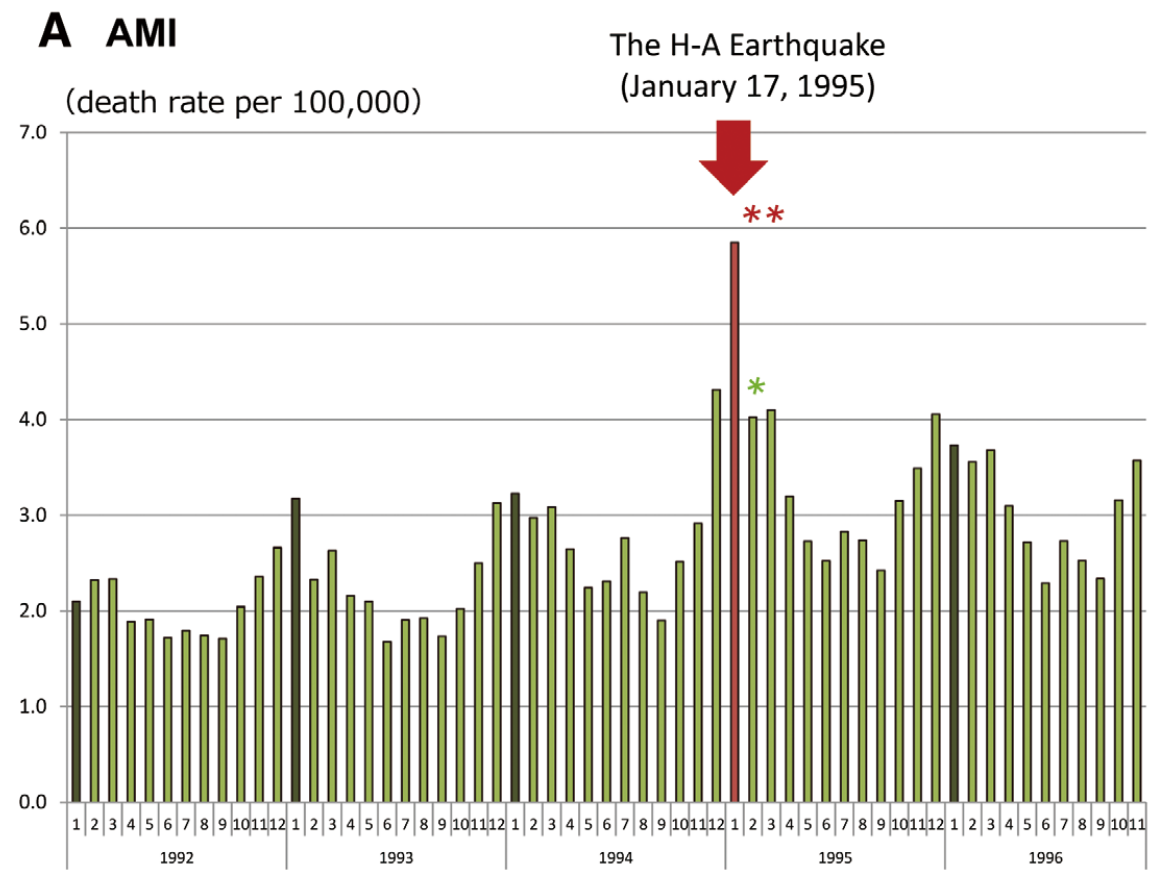

\section{B Stroke}

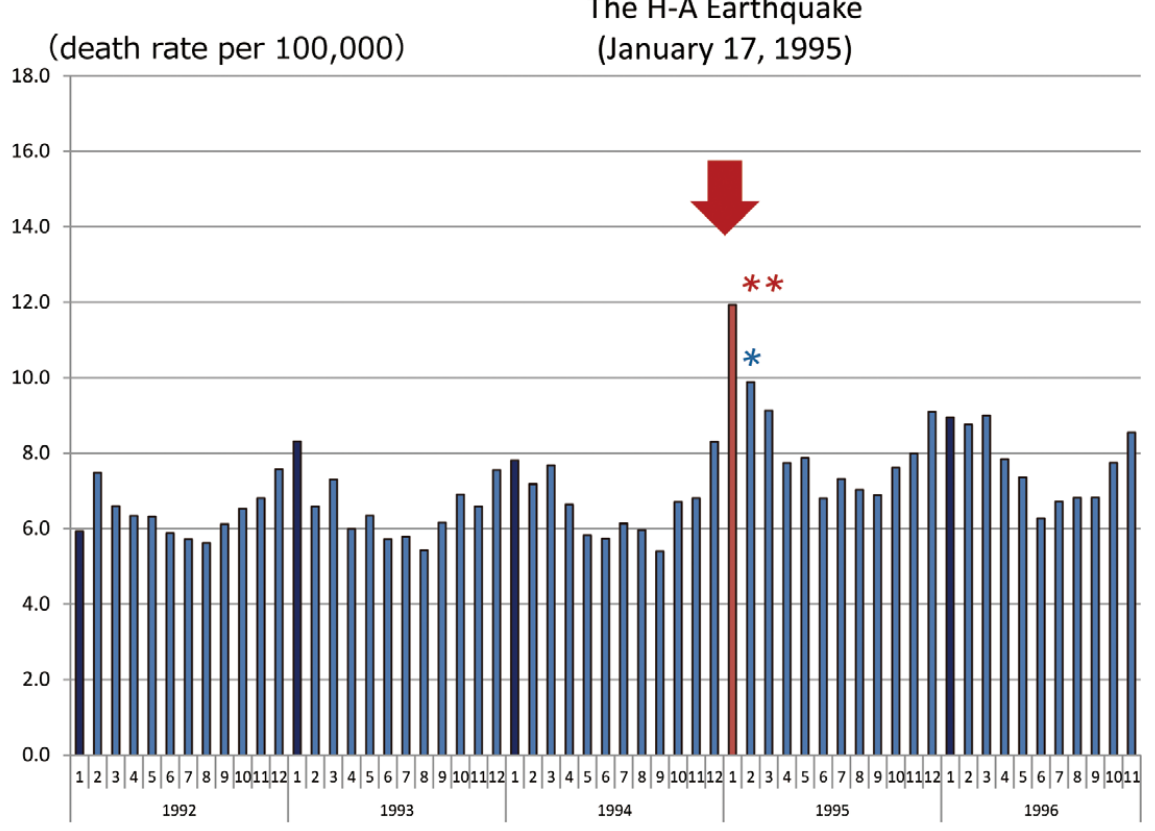

Figure 3. Number of deaths from January 11, 1992 to December 10, 1996 from AMI (A) and stroke (B) in Hyogo, Osaka, and Kyoto prefectures. Red arrows indicate the occurrence of the Great Hanshin-Awaji $(\mathrm{H}-\mathrm{A})$ Earthquake. ${ }^{\star} \mathrm{P}<0.001$, ${ }^{\star \star} \mathrm{P}<0.05$ : comparison with the reference, which was the number of AMI and stroke deaths in the same months in 1996. AMI, acute myocardial infarction.

quake, and in 2005, the Japanese government's Central Disaster Prevention Council revised the Basic Disaster Management Plan to include full deployment of DMATs to disaster areas. ${ }^{18}$ DMAT is defined as a trained, mobile, self-contained medical team that can act in the acute phase of a disaster to provide medical treatment in a devastated area. As a result, medical teams that were part of DMAT conducted fact-finding, onsite medical rounds, and evaluated medical needs, but there were 
A AMI after the GEJ Earthquake

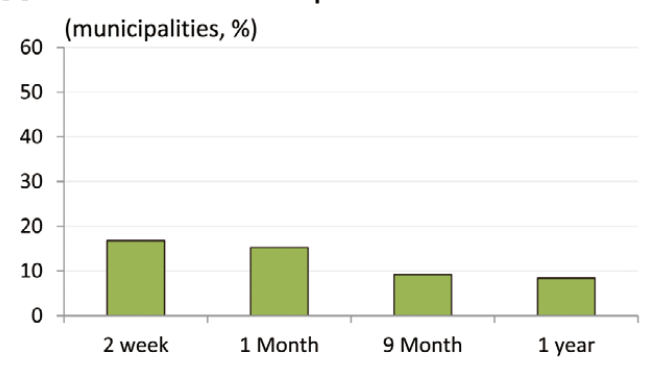

C AMI after the H-A Earthquake

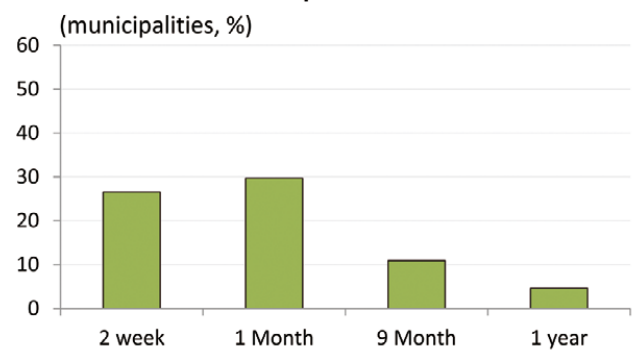

B Stroke after the GEJ Earthquake

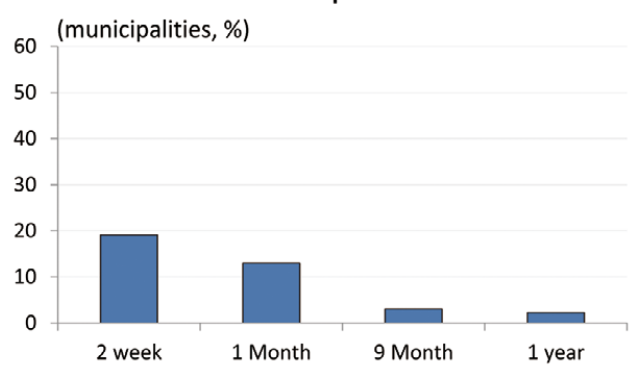

D Stroke after the H-A Earthquake

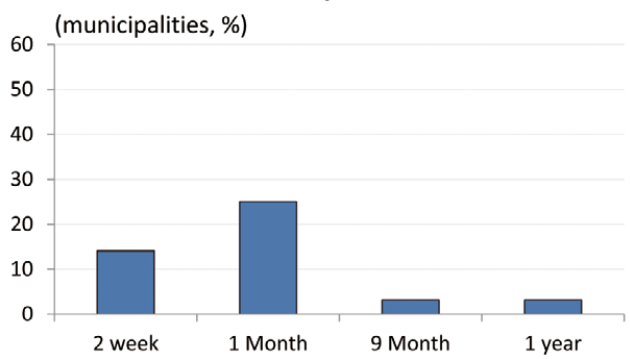

Figure 4. Percentage of municipalities with a standardized mortality ratio (SMR) $\geq 2$ for acute myocardial infarction (AMI) and stroke for 2 weeks, 1 month, 9 months and 1 year following the Great East Japan (GEJ) Earthquake and the Great Hanshin-Awaji $(\mathrm{H}-\mathrm{A})$ Earthquake. SMR of (A) AMI and (B) stroke after the GEJ Earthquake, and the SMR of (C) AMI and (D) stroke after the H-A Earthquake.

\section{A AMI after the GEJ Earthquake}
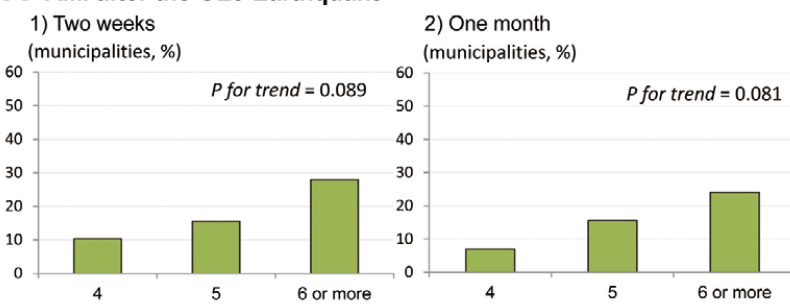

C AMI after the H-A Earthquake

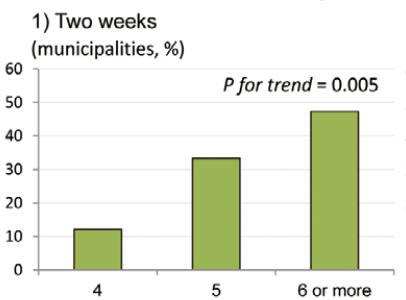

2) One month

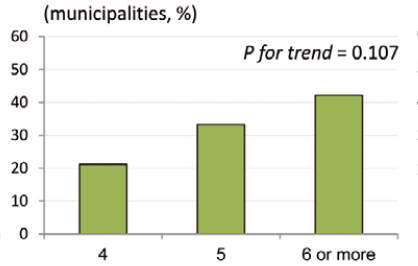

(municipalities, \%)
B Stroke after the GEJ Earthquake

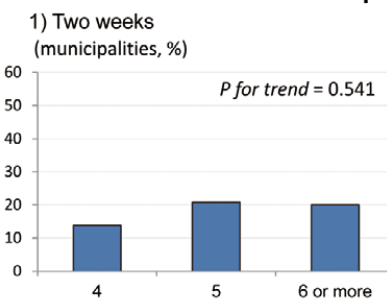

2) One month (municipalities, \%)

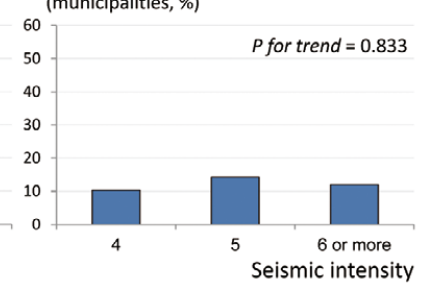

D Stroke after the H-A Earthquake
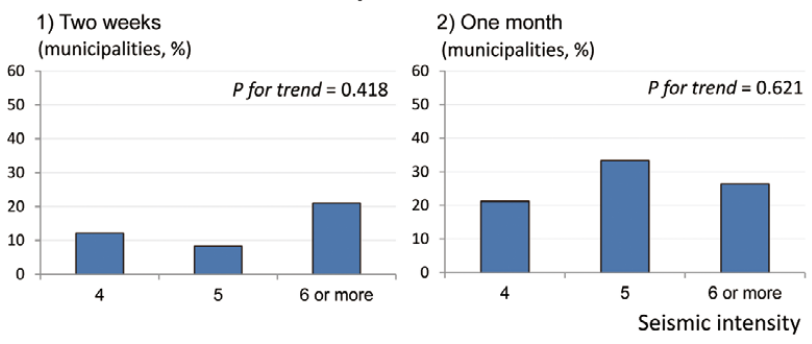

Figure 5. Association between the standardized mortality ratio (SMR) of acute myocardial infarction (AMI) and stroke mortality and seismic intensity for 2 weeks and for 1 month following the Great East Japan (GEJ) Earthquake and the Great Hanshin-Awaji $(\mathrm{H}-\mathrm{A})$ Earthquake. *The graph shows percentage of municipalities with SMR $\geq 2$ for AMI and stroke. The SMR of AMI for 2 weeks (A-1) and 1 month (A-2), the SMR of stroke for 2 weeks (B-1) and 1 month (B-2) after the GEJ Earthquake. The SMR of AMI for 2 weeks (C-1) and 1 month (C-2), the SMR of stroke for 2 weeks (D-1) and 1 month (D-2) after the H-A Earthquake. 
few severely injured persons in the GEJ Earthquake. ${ }^{19}$ Also, improved survival could be the result of advances that occurred between 1995 and 2011 in AMI treatment and in emergency transfer systems. In fact, Hao et al reported that according to the Miyagi AMI Registry Study, emergency care of AMI improved soon after the GEJ Earthquake when compared with the previous 3 years; early admission after symptom onset and a higher rate of performing primary percutaneous coronary intervention were contributing factors. ${ }^{20,21}$ In addition, the smaller increase in AMI mortality for the GEJ Earthquake as compared with the H-A Earthquake may have been related to the fact that the proportion of individuals with a high risk for AMI was greater among those who died as a result of the tsunami. However, the denominator used in calculating incidence was the population, and when the victims of the tsunami were excluded, there was little effect on incidence.

In the GEJ Earthquake, an increase in stroke mortality as compared with the previous 3 years was seen for 2 months after the earthquake, while an increase in AMI mortality was seen for 1 month. In addition to the acute stress experienced at the time of a disaster, the increase in AMI seen after earthquakes may be caused by sympathetic activation resulting from chronic stress such as subsequent evacuation, aftershocks, sleep disturbance, and a sense of loss. ${ }^{22}$ The activated sympathetic nervous system will increase blood pressure and heart rate, as previously reported. ${ }^{23,24,25}$ With regard to stroke, the possibility has been raised that increases in blood pressure were caused by stress after the Noto earthquake. ${ }^{26}$ For the GEJ Earthquake, increases in blood pressure may have been exacerbated by the loss of regular medications because of flooding or temporary medication shortages. Systolic blood pressure reportedly increased by $12 \mathrm{mmHg}$ after the GEJ Earthquake. ${ }^{27}$ Although strong aftershocks occurred for 1 month after the GEJ Earthquake, only the incidence of stroke appeared to be affected; there were no effects on acute coronary syndrome. The prolonged effect on stroke mortality may be caused by the largest aftershock ${ }^{7}$ and/or continuous elevation of blood pressure associated with emotional stress. ${ }^{26}$ However, because the mechanisms underlying these processes cannot be determined epidemiologically, investigations that use a variety of approaches, including experimental approaches, are needed.

There are few previous studies that have examined the association between seismic intensity and CVD. With its seismic intensity of 6.3 or more, there was an increased stroke incidence for 1 year after the H-A Earthquake. ${ }^{10}$ In the present study, stroke death had no association with seismic intensity after the GEJ or H-A Earthquake. These somewhat contradictory results might be caused by differences in occurrence and stroke death as an outcome, and differences in the cut-off point of seismic intensity. The association might be present if seismic intensity is more severe. On the other hand, the relationship between deaths as the result of AMI and total destruction of homes was reported for the H-A Earthquake. The complete destruction of one's home because of seismic intensity could be considered a surrogate loss. ${ }^{5}$ Some other factors might have a greater influence than seismic intensity for the increase in CVD mortality after a major earthquake. For instance, earthquake survivors must seek shelter and/or live without daily necessities and medicines. They also experience grief related to loss. In addition, the GEJ Earthquake caused extensive tsunami damage. These factors might confound the present results at the municipal level. Further research is necessary to identify factors affecting CVD-related mortality after earthquakes.

\section{Study Strengths and Limitations}

The present study was based on a review of all death certificates. We reported increased cardiovascular mortality after both the $1995 \mathrm{H}-\mathrm{A}$ Earthquake and the 2011 GEJ Earthquake. However, there are several limitations to this study. First, there is a possibility of misclassification of the cause of death, because there was no consistent verification by autopsy. Second, this analysis was at the municipal level. Therefore, we could not include detailed individual data, such as the degree of quake damage, experience of loss, or clinical characteristics. Third, the relationship between seismic intensity and stroke warrants further investigation, as we could not calculate the SMR of each subtype of stroke in each municipality because of the small sample size, especially for cerebral hemorrhage. Fourth, death certificates were filed at the municipalities even if the persons had moved away or if they were temporarily evacuated after the disaster. In the case of the Fukushima Daiichi Nuclear accident, there were special regulations concerning evacuees. In other words, the certificates reflected the number of inhabitants at the time of the GEJ Earthquake. Fifth, we selected 2 different regions with differing levels of earthquake damage for examination. Because there are no standards for defining disaster areas, the 3 prefectures most heavily damaged in the GEJ Earthquake were selected, as well as the 3 prefectures most heavily damaged in the H-A Earthquake. In the H-A Earthquake, more than $90 \%$ of the casualties were concentrated in Hyogo prefecture. Although the results of the analysis limited to Hyogo prefecture did not differ greatly from the results of the 3 prefectures combined, caution is needed in interpreting the comparisons. Finally, there were major differences between the regions where the 2 earthquakes occurred, the years in which they occurred, and the damage that resulted. The results of this study imply that a variety of unidentified factors that have not been quantified (eg, advances in medical technology between the 2 earthquakes and access to medical facilities and lifestyle changes in the regions) may be related to the increase in CVD seen after the earthquakes. Caution is therefore needed in interpreting the results. Despite these limitations, our findings provide valuable information for future planning. The increase in CVD deaths after both earthquakes suggests that countermeasures should be developed to prevent deaths after major earthquakes.

\section{Conclusions}

We presented our findings of increased mortality from AMI and stroke following the GEJ and H-A Earthquakes. Our results indicate that both earthquakes were associated with an acute increase in cardiovascular mortality. The effect of disaster was sustained for months after the H-A Earthquake, compared with a limited effect after the GEJ Earthquake. The increased AMI mortality was associated with seismic intensity in a dose-response manner, but there was no association with stroke mortality.

\section{Acknowledgments}

Funding: This study was supported by grants from the Ministry of Health, Labour and Welfare, Japan.

\section{Disclosures}

The authors have no conflicts of interest to disclose. 


\section{References}

1. The Report on Damage from the East Japan Earthquake. (No. 150) Fire and Disaster Management Agency, September 10, 2014. Available at: http://www.fdma.go.jp/bn/higaihou/pdf/jishin/150.pdf (accessed February 20, 2015).

2. Leor J, Poole WK, Kloner RA. Sudden cardiac death triggered by an earthquake. N Engl J Med 1996; 334: 413-419.

3. Trichopoulos D, Katsouyanni K, Zavitsanos X, Tzonou A, DallaVorgia P. Psychological stress and fatal heart attack: The Athens (1981) earthquake natural experiment. Lancet 1983; 1: 441-444.

4. Trevisan M, Celentano E, Meucci C, Farinaro E, Jossa F, Krogh V, et al. Short-term effect of natural disasters on coronary heart disease risk factors. Arteriosclerosis 1986; 6: 491-494.

5. Ogawa K, Tsuji I, Shiono K, Hisamichi S. Increased acute myocardial infarction mortality following the 1995 Great Hanshin-Awaji earthquake in Japan. Int J Epidemiol 2000; 29: 449-455.

6. Aoki T, Fukumoto Y, Yasuda S, Sakata Y, Ito K, Takahashi J, et al. The Great East Japan Earthquake Disaster and cardiovascular diseases. Eur Heart J 2012; 33: 2796-2803.

7. Aoki T, Takahashi J, Fukumoto Y, Yasuda S, Ito K, Miyata S, et al. Effect of the Great East Japan Earthquake on cardiovascular diseases: Report from the 10 hospitals in the disaster area. Circ J 2013; 77: 490-493.

8. Niiyama M, Tanaka F, Nakajima S, Itoh T, Matsumoto T, Kawakami $\mathrm{M}$, et al. Population-based incidence of sudden cardiac and unexpected death before and after the 2011 earthquake and tsunami in Iwate, northeast Japan. J Am Heart Assoc 2014; 3: e000798, doi: 10.1161/JAHA.114.000798.

9. Nakamura M, Tanaka F, Nakajima S, Honma M, Sakai T, Kawakami $\mathrm{M}$, et al. Comparison of the incidence of acute decompensated heart failure before and after the major tsunami in Northeast Japan. Am J Cardiol 2012; 110: 1856-1860.

10. Sokejima S, Nakatani Y, Kario K, Kayaba K, Minowa M, Kagamimori S. Seismic intensity and risk of cerebrovascular stroke: 1995 HanshinAwaji earthquake. Prehosp Disaster Med 2004; 19: 297-306.

11. The Report on Damage from the Great Hanshin-Awaji Earthquake. (Final reports.) Fire and Disaster Management Agency, May 19, 2006. Available at: http://www.fdma.go.jp/data/010604191452374961.pdf (accessed February 20, 2015).

12. The report on death in the Great Hanshin-Awaji Earthquake from death certificate data. Ministry of Health, Labour and Welfare, 2000. Available at: http://www.mhlw.go.jp/toukei/saikin/hw/jinkou/kakutei95/ dL/h7_gaiyo.pdf (accessed February 20, 2015) (in Japanese).

13. White Paper on Disaster Management 2011 Executive Summary. (Provisional Translation.) Cabinet Office, Government of Japan. Available at: http://www.bousai.go.jp/kaigirep/hakusho/pdf/WPDM2011_ Summary.pdf (accessed February 20, 2015).

14. Annual reports of Population Estimation. Ministry of Internal Affairs and Communications with the collaboration of Ministries and Agencies, 1995-2014.

15. Database of Seismic Intensity. Japan Meteorological Agency. Avail- able at: http://www.data.jma.go.jp/svd/eqdb/data/shindo/index.php (accessed February 20, 2015).

16. Kloner RA, Leor J, Poole WK, Perritt R. Population-based analysis of the effect of the Northridge Earthquake on cardiac death in Los Angeles County, California. J Am Coll Cardiol 1997; 30: 11741180 .

17. Nakagawa I, Nakamura K, Oyama M, Yamazaki O, Ishigami K, Tsuchiya Y, et al. Long-term effects of the Niigata-Chuetsu earthquake in Japan on acute myocardial infarction mortality: An analysis of death certificate data. Heart 2009; 95: 2009-2013.

18. Fuse A, Yokota H. An analysis of Japan Disaster Medical Assistance Team (JDMAT) deployments in comparison with those of JDMAT's counterpart in the United States (USDMAT). J Nippon Med Sch 2010; 77: 318-324.

19. Fuse A, Igarashi Y, Tanaka T, Kim S, Tsujii A, Kawai M, et al. Onsite medical rounds and fact-finding activities conducted by Nippon Medical School in Miyagi prefecture after the Great East Japan Earthquake 2011. J Nippon Med Sch 2011; 78: 401 -404.

20. Hao K, Takahashi J, Ito K, Miyata S, Sakata Y, Nihei T, et al. Emergency care of acute myocardial infarction and the great East Japan earthquake disaster. Circ J 2014; 78: 634-643.

21. Ishii H, Yamamoto T, Murohara T. Emergency care for acute myocardial infarction in disasters. Circ J 2014; 78: 586-587.

22. Kario K, Matsuo T, Kobayashi H, Yamamoto K, Shimada K. Earthquake-induced potentiation of acute risk factors in hypertensive elderly patients: Possible triggering of cardiovascular events after a major earthquake. J Am Coll Cardiol 1997; 29: 926-933.

23. Fuster V, Badimon L, Badimon JJ, Chesebro JH. The pathogenesis of coronary artery disease and the acute coronary syndromes (1). $N$ Engl J Med 1992; 326: 242-250.

24. Esler M, Kaye D. Sympathetic nervous system activation in essential hypertension, cardiac failure and psychosomatic heart disease. $J$ Cardiovasc Pharmacol 2000; 35: S1-S7.

25. Ohira T, Iso H. Cardiovascular disease epidemiology in Asia: An overview. Circ J 2013; 77: 1646-1652.

26. Tsuchida M, Kawashiri MA, Teramoto R, Takata M, Sakata K, Omi $\mathrm{W}$, et al. Impact of severe earthquake on the occurrence of acute coronary syndrome and stroke in a rural area of Japan. Circ J 2009; 73: $1243-1247$.

27. Satoh M, Kikuya M, Ohkubo T, Imai Y. Acute and subacute effects of the great East Japan earthquake on home blood pressure values. Hypertension 2011; 58: e193-e194, doi:10.1161/ HYPERTENSIONAHA.111.184077.

\section{Supplementary Files}

Supplementary File 1

Table S1. Sex and age distributions in the year of each Earthquake in the study areas

Please find supplementary file(s);

http://dx.doi.org/10.1253/circj.CJ-15-0223 